\title{
WOOD DRYING IN HIGH AIR TEMPERATURE
}

\author{
Aivars Aboltins ${ }^{1}$, Jan Papez ${ }^{2}$, Pavel Kic ${ }^{2}$ \\ ${ }^{1}$ Latvia University of Agriculture; ${ }^{2}$ Czech University of Life Sciences Prague \\ aivars.aboltins@1lu.lv, kic@tf.czu.cz,janpapez@tiscali.cz
}

\begin{abstract}
The aim of this paper is to present the methodology of measurement of moisture content of wood and show some results of this measurement in application on small pieces of wood. Fresh wood from the tree has rather high content of moisture, which makes it not suitable for use in constructions or industry processing. The usual drying methods are based on drying with lower air temperature, and the drying process lasts long time. This paper describes the theory and experimental results of wood drying by high temperature of $105^{\circ} \mathrm{C}$. Using the experimental data with the natural convective drying method in the laboratory conditions under high temperature there were calculated the theoretical drying coefficients, useful for description and modelling of the drying process, the calculated theoretical results of moisture removal and compared with the experimental results obtained from the measurements. The obtained results of this research are parameters, which can be used for other research work and for improvement of the whole drying process.
\end{abstract}

Keywords: wood pieces, oven, natural convection, drying coefficient.

\section{Introduction}

The aim of this paper is to present the methodology of measurement of moisture content of wood and show some results of this measurement in application on small pieces of wood. Fresh wood from the tree has rather high content of moisture, which makes it not suitable for use in constructions or industry processing. The usual drying methods are based on drying with lower air temperature, and the drying process lasts long time. This paper describes the theory and experimental results of wood drying by high temperature of $105^{\circ} \mathrm{C}$.

As timber coniferous and deciduous trees are used. Spruce (Picea abies) is the most important timber tree used in the Czech Republic. There is used also the wood of spruce silver fir (Albies alba), scots pine (Pinus silvestris), larch (Larix decidua), oak (Quercus robur), beech (Fagus silvatica), black poplar (Populus nigra), alder (Aldus glutinosa) and exotic wood [1;2]. Besides the solid wood, also a wide range of wood-based materials are used, e.g., plywood boards, agglomerated boards, veneers, chipboards etc. The main aspects of material selection are not only the mechanical and physical properties, but also the price, availability and aesthetic aspects [3;4].

The use of wood is very common especially in the countries with large areas covered with forests, where the source of wood as a raw material for different purposes is available in very good quality. Among these countries all Scandinavian countries, the Baltic States (Estonia, Latvia, and Lithuania) as well as other European, and, of course, many non-European countries can be mentioned.

Protection of wooden buildings means primarily the following measures: selection of appropriate types of wood and wooden materials (using wood with a relatively high strength), ensuring the quality of timber, prevention of wood against increased moisture, and respecting the fire safety principles [4].

Wood, wooden products and structures must grant the limits of moisture to prevent formation of cracks and especially the activity of biological pests. Unnecessary and excessive wetting of wood can be more or less successfully prevented by the following measures: shape optimization of timber products, wood insulation from water sources and regulation of climatic conditions (suppression of water condensate) [4].

Moisture has a great importance in the processing and use of wood. Wood as a hygroscopic material reacts to the moisture conditions of the environment, which is reflected in shaped changes (swelling and shrinking), and moreover, if the moisture is about $20 \%$ or more in combination with suitable temperature $\left(15^{\circ} \mathrm{C}\right.$ or more) there are suitable conditions for insects and fungi invading and decaying the wood $[5 ; 6]$.

Therefore, this paper includes the theoretical study of changes of the moisture content in wood in response to the high temperature of the drying air. The aim of this research was to investigate the theoretical background of wood drying by high temperatures and determination of the drying coefficients. 


\section{Materials and methods}

For studies we have selected five types of wood: oak (Quercus robur), beech (Fagus silvatica), spruce (Picea abies), scots pine (Pinus silvestris), and larch (Larix decidua). To be able to study different ways of drying up the water from the wood, two samples of each type of wood were examined (larger and smaller length) (Fig. 1). The exact dimensions and properties of the tested samples are presented in Tables 1 and 2.

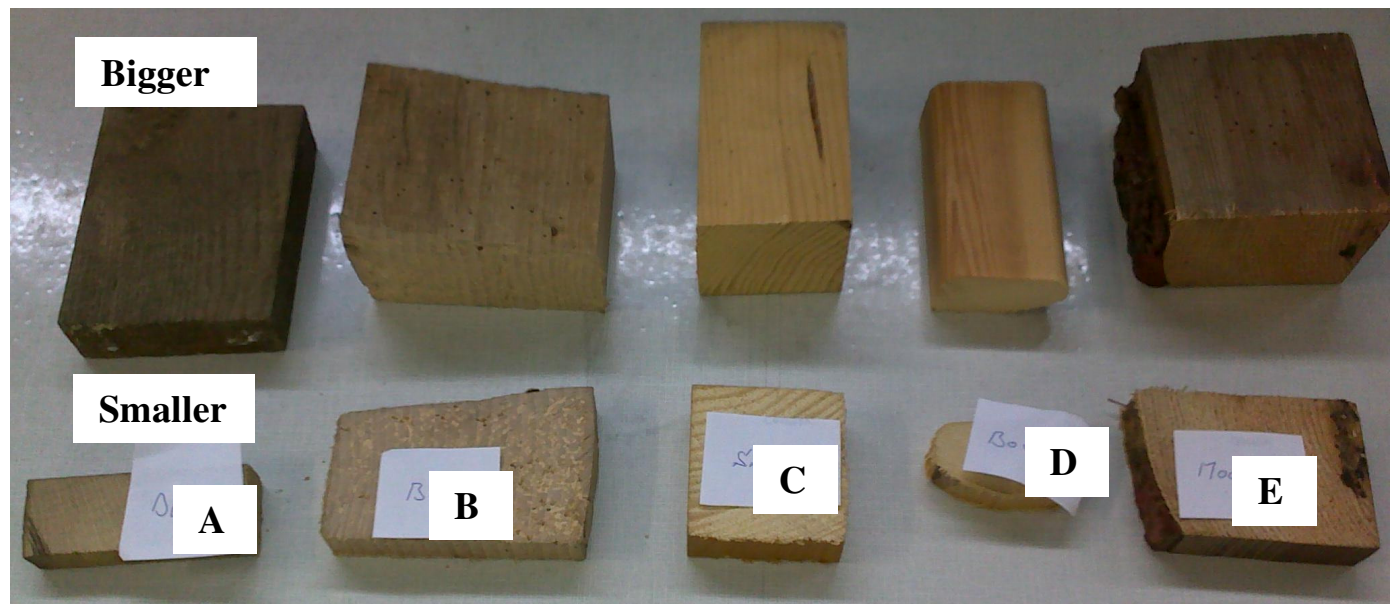

Fig. 1. Samples of wood used for drying measurement. Bigger samples on upper row and smaller samples on bottom row: A - oak (Quercus robur); B - beech (Fagus silvatica); $\mathrm{C}$ - spruce (Picea abies); D - scots pine (Pinus silvestris); E - larch (Larix decidua)

Table 1

Bigger samples of wood used for drying measurements

\begin{tabular}{|c|c|c|c|c|}
\hline Type of wood & Weight, $\mathbf{g}$ & Density, $\mathbf{~ k g} \cdot \mathbf{m}^{-3}$ & $\begin{array}{c}\text { Sample profile } \\
\mathbf{m m} \mathbf{x ~ m m}\end{array}$ & Length, mm \\
\hline Oak & 229.35 & 725 & $93 \times 33$ & 103 \\
\hline Beech & 367.18 & 720 & $100 \times 60$ & 85 \\
\hline Spruce & 190.96 & 450 & $67 \times 68$ & 93 \\
\hline Pine & 100.00 & 535 & $55 \times 34$ & 100 \\
\hline Larch & 295.21 & 590 & $88 \times 65$ & 88 \\
\hline
\end{tabular}

Table 2

Smaller samples of wood used for drying measurements

\begin{tabular}{|c|c|c|c|c|}
\hline Type of wood & Weight, $\mathbf{g}$ & Density, $\mathbf{~ k g} \cdot \mathbf{m}^{-3}$ & $\begin{array}{c}\text { Sample profile } \\
\mathbf{m m} \mathbf{x ~ m m}\end{array}$ & Length, mm \\
\hline Oak & 46.33 & 725 & $93 \times 33$ & 21 \\
\hline Beech & 110.99 & 720 & $100 \times 60$ & 25 \\
\hline Spruce & 48.90 & 450 & $67 \times 68$ & 24 \\
\hline Pine & 18.39 & 535 & $55 \times 34$ & 18 \\
\hline Larch & 79.17 & 590 & $88 \times 65$ & 23 \\
\hline
\end{tabular}

The determination of wood moisture was carried out by the gravimetric method; that is a direct method and the results are very accurate. For drying of samples of spruce wood the electric oven Memmert UNB with automatic control of temperature and natural flow of air inside the chamber was used. The samples were weighed on the digital laboratory balance KERN-440-35N with maximum load weight $400 \mathrm{~g}$ and with resolution $0.01 \mathrm{~g}$. The total drying time was adapted to the need for determination of the final moisture content.

Using the experimental data with the natural convective drying method in the laboratory conditions under high temperature $105^{\circ} \mathrm{C}$ the theoretical drying coefficients, useful for description and modelling of the drying process were calculated, the theoretical results of moisture removal were calculated and compared with the experimental results obtained from the measurements. The results of 
drying of different sample dimensions and small mass of wood pieces are compared. The obtained results of this research are parameters, which can be used for the future research work and for improvement of the whole drying process. This destructive method of measurement can be also used for laboratory control of another method of measurement, e.g., non-destructive sensor tests, based on other physical principles (capacitive or resistive) sensors [6].

\section{Mathematical model}

In order to determine the effective moisture diffusion in solid wood we use the mass maintenance law usually presented in the following form:

$$
\frac{\partial \widetilde{c}}{\partial t}=\operatorname{div}(D \operatorname{grad} \widetilde{c})
$$

where $D$ - coefficient of diffusion;

$\tilde{c}(x, y, z, t)$ - concentration of moisture in wood;

$x, y, z$ - space coordinates,

$t$ - time.

Since diffusion of vapours in the wood fibre direction is several times greater than in the radial and tangential ones [7;8] and the surface of the fibre direction of the samples is greater than the surfaces of radial and tangential directions, we choose a 1-dimentional model with $D_{x}$ in the fibre direction (diffusion in a plane sheet $\tilde{c}(x, y, z, t) \approx c(x, t))$.

$$
\frac{\partial c}{\partial t}=\frac{\partial}{\partial x}\left[D_{x} \frac{\partial c}{\partial x}\right]
$$

We have a case where diffusion occurs through all surfaces of samples and assume that the diffusion coefficient $D_{x}$ is a constant. In moment $t=0$ concentration of moisture in the sample of wood is constant $C_{S}$. The water vapour concentration on surfaces is constant $c(x, t)=0$. In our case we can considered the diffusion process as a symmetrical situation and get the mathematical problem:

$$
\begin{gathered}
\frac{\partial c}{\partial t}=D_{x} \frac{\partial^{2} c}{\partial x^{2}} \quad-l<x<l, \quad t>0(3) \\
\left.c\right|_{t=0}=c_{s} \\
\left.c\right|_{x=-l}=\left.c\right|_{x=l}=0
\end{gathered}
$$

where $2 l$ - length of sample in $\mathrm{x}$ direction.

The problem (3) - (5) with $D_{x}=$ const solution is according to [9]:

$$
c(x, t)=\frac{4 c_{s}}{\pi} \sum_{n=0}^{\infty} \frac{(-1)^{n}}{2 n+1} \cdot e^{-\frac{D_{x}(2 n+1)^{2} \pi^{2} \cdot t}{4 l^{2}}} \cdot \cos \frac{(2 n+1) \pi \cdot x}{2 l}
$$

If $M_{t}$ denotes the amount of diffusing moisture, which has come out from the material at time $t$, and $M_{\infty}$ the corresponding quantity after infinite time, then [9]:

$$
\frac{M_{t}}{M_{\infty}}=1-\sum_{n=0}^{\infty} \frac{8}{(2 n+1)^{2} \pi^{2}} \cdot e^{-\frac{D_{x}(2 n+1)^{2} \pi^{2} t}{4 l^{2}}}
$$

At first we must estimate $D_{x}$. Looking at the series (7), we see that it converges very fast and that is why we choose only the first member of the series and expression (7) becomes

$$
\frac{8}{\pi^{2}} \cdot e^{-\frac{D_{X} \cdot \pi^{2} \cdot t}{4 l^{2}}}=1-\frac{M_{t}}{M_{\infty}}
$$


Right-hand side of the equation (8) is known (experimental data at time $t=t_{i}$ ) and can express the coefficient of diffusion $C$ :

$$
D_{x}=-\frac{4 l^{2} \ln \left(\frac{\pi^{2}\left(M_{\infty}-M_{t}\right)}{8 \cdot M_{\infty}}\right)}{\pi^{2} \cdot t}
$$

We can calculate $D_{x}{ }^{i}$ for each experimental measurement at time $t_{i}$ from (9) and find $D_{x}=$ const as

$$
D_{x}=\frac{1}{k} \sum_{i=1}^{k} D_{x}^{i},
$$

where $k$ - number of measurements.

If $D_{x}$ depending on the drying time $D_{x}=D_{x}(t)$, we can use the methodology [10] and find the expression of $D_{x}(t)$. For solving (2), (4), (5) with $D_{x}(t)$ we can use difference schemes [11; 12].

\section{Results and discussion}

One of the most important tasks is to find the value (expression) for the drying coefficient $K$. In our situation we can consider the drying coefficient as the moisture diffusion coefficient $D$. It depends on the dried product, drying equipment, conditions, etc. All samples at the beginning of the experiment had the same humidity $-14 \%$. The results and calculated diffusion coefficients for smaller samples (Table 2) of wood can be seen in Table 3

Table 3

\section{Calculated diffusion coefficients of smaller wood samples used for drying measurements}

\begin{tabular}{|c|c|c|c|c|}
\hline \multirow{2}{*}{$\begin{array}{c}\text { Type of } \\
\text { wood }\end{array}$} & \multicolumn{2}{|c|}{ First 10 hours drying } & \multicolumn{2}{c|}{ 24 hours drying } \\
\cline { 2 - 5 } & $\begin{array}{c}\text { Average diffusion } \\
\text { coefficient, } \mathrm{m}^{2} \cdot \mathrm{s}^{-1}\end{array}$ & $\begin{array}{c}\text { Standard derivation of } \\
\text { coefficient, } \mathrm{m}^{2} \cdot \mathrm{s}^{-1}\end{array}$ & $\begin{array}{c}\text { Average diffusion } \\
\text { coefficient, } \mathrm{m}^{2} \cdot \mathrm{s}^{-1}\end{array}$ & $\begin{array}{c}\text { Standard derivation of } \\
\text { coefficient, } \mathrm{m}^{2} \cdot \mathrm{s}^{-1}\end{array}$ \\
\hline Beech & $7.91 \cdot 10^{-9}$ & $1.26 \cdot 10^{-9}$ & $6.01 \cdot 10^{-9}$ & $1.82 \cdot 10^{-9}$ \\
\hline Spruce & $7.74 \cdot 10^{-9}$ & $2.27 \cdot 10^{-9}$ & $6.08 \cdot 10^{-9}$ & $2.33 \cdot 10^{-9}$ \\
\hline Pine & $5.41 \cdot 10^{-9}$ & $2.25 \cdot 10^{-9}$ & $4.22 \cdot 10^{-9}$ & $2.19 \cdot 10^{-9}$ \\
\hline Larch & $6.30 \cdot 10^{-9}$ & $1.48 \cdot 10^{-9}$ & $4.68 \cdot 10^{-9}$ & $1.63 \cdot 10^{-9}$ \\
\hline Oak & $5.81 \cdot 10^{-9}$ & $1.15 \cdot 10^{-9}$ & $4.86 \cdot 10^{-9}$ & $1.15 \cdot 10^{-9}$ \\
\hline
\end{tabular}

As it can be seen from the results of the average diffusion coefficients, in the first 10 drying hours they are higher (more than $20 \%$ ) than the average diffusion coefficient in all drying time. Its means that the water diffusion coefficient depends on the water concentration in the samples.

The average diffusion coefficients calculated from 24 hours drying are similar to the presented in [8]. Comparison of the experimental and theoretical data, with 24 hours average diffusion coefficients (Table 3), we can see in Fig. 2 and Fig. 3.

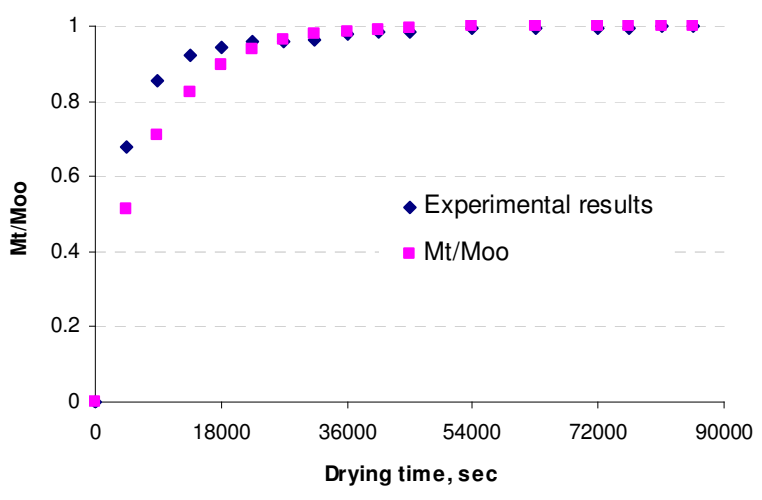

Fig. 2. Experimental and theoretical (7) data comparison for spruce (Picea abies) sample

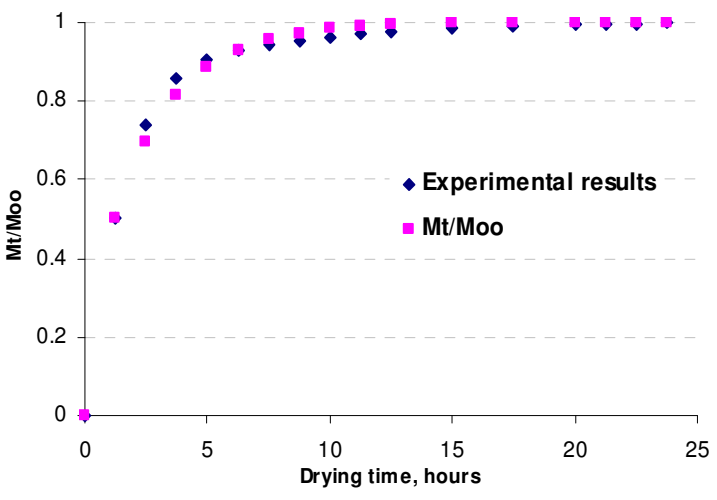

Fig. 3. Experimental and theoretical (7) data comparison for oak (Quercus robur) sample 
As it can be seen, in the case of spruce the data difference is greater than the oak results. The experimental data showed that the diffusion coefficient of spruce ranged from $3.95 \cdot 10^{-9}-11 \cdot 10^{-9} \mathrm{~m}^{2} \cdot \mathrm{s}^{-1}$, i.e. the spruce sample was observed in the highest moisture concentration effects on the diffusion coefficient compared to all other samples. We can see that the effect of the oak sample moisture concentration on the diffusion coefficient was the smallest. The water diffusion coefficient in the oak sample ranged from $3.65 \cdot 10^{-9}-6.85 \cdot 10^{-9} \mathrm{~m}^{2} \cdot \mathrm{s}^{-1}$ during the drying experiment.

\section{Conclusions}

1. The proposed methodology, originally used for determination of the drying coefficient of wood.

2. Average calculation diffusion coefficients in first 10 drying hours are higher (more than $20 \%$ ) than the average diffusion coefficient in all drying time $(24 \mathrm{~h})$. Its means that the water diffusion coefficient depends on the water concentration in wood samples.

3. It is necessary to use the variable diffusion coefficient to more accurately simulate the wood drying process.

\section{References}

1. Hujnak J. Timber structures and components. SNTL, Praha, 1986, 192 p. (in Czech)

2. Vavrcik H., Gryc V. Description of selected types of wood and their uses. All about wood in interior and exterior. 8(2), 2008, pp. 15-18. (in Czech)

3. Kral P. 2008. No wood as wood. All about wood in interior and exterior. 8(2), pp. 22-29. (in Czech)

4. Stefko J., Reinprecht L., Kuklik P. Timber structures: construction, protection and maintenance. JAGA GROUP, spol s r. o., Bratislava, 2009, 196 pp. (in Czech)

5. Holan J. Against what the timber must be protected. All about wood in interior and exterior. 8(2), 2008, pp. 128-132. (in Czech)

6. Papez J., Kic P. Wood Moisture of Rural Timber Constructions. Agronomy Research, vol. 11, No 2, 2013, pp. 505-512 [6]

7. Aboltins A., Buikis A., Cepitis J., Kalis H., Reinfelds A. Diffusion and Chemical Attachment of Substances with Simple Molecular Structure in Wood, Progress in Industrial mathematics at ECMI98, Edited by L. Arkeryd, J.Bergh, P.Brenner and R. Pettersson, B.G.Teubner Stuttgart Leipzig 1999, pp.188-195

8. Shubin G.S. Wood heat treatment and drying, Lesnaja promishlenostj, Moscow, 1990, (in Russian)

9. Crank J. The mathematics of diffusion. Oxford, Clarendon Press, 1956, 347 p.

10. Aboltins A. Theoretical study of material drying coefficient; Engineering for Rural Development International Scientific Conference. 2013, pp. 153-158.

11. Samarskii A.A. The theory of difference schemes, Nauka, Moscow, 1988, (in Russian)

12. Aboltins A., Morozovs A. Solid wood impregnation process with acetic anhydride computer modelling, Fourth Nordic-Baltic agrometrics conference, Conference proceedings Edit. U.Olsson, J.Seek Uppsala, 2003, pp. 1-8. 